\title{
ESCOLHAS, VIVÊNCIAS E CIRCUNSTÂNCIAS NO MEMORIAL DE FORMAÇÃO DE PROFESSORES DE MATEMÁTICA ${ }^{1}$
}

- IARA LETÍCIA LEITE DE OLIVEIRA

Universidade Estadual Paulista “Júlio de Mesquita Filho" - campus Rio Claro

- ROSANA AREAL DE CARVALHO

Universidade Federal de Ouro Preto

FERNANDA APARECIDA OLIVEIRA RODRIGUES SILVA

Universidade Federal de Ouro Preto

RESUMO Este artigo é fruto dos resultados de uma dissertação que teve como objetivo tecer compreensões sobre aspectos da trajetória formativa de professores de Matemática, ao narrarem suas histórias de vida por meio do memorial. A pesquisa pautou-se pelo método autobiográfico e contou com a colaboração de seis professores de Matemática, que escreveram memoriais de formação interpretados à luz da análise de convergências e singularidades. 0 movimento de tornarse professor é permanente e ocorre por meio das diversas vivências em que vários cenários os vão constituindo enquanto professores de Matemática. Ao analisarmos essas narrativas, encontramos a família e os professores exercendo um papel fundamental na escolha da profissão. A formação dá-se sob a influência dos professores, o gosto pela área ou as pequenas vivências da profissão, sejam nas experiências em sala de aula, nas brincadeiras ou em outros locais. Alguns elementos, como a aproximação e as afinidades com a Matemática e a referência a si mesmo como bom aluno, são fatores presentes na opção pela carreira educacional. Embora envolvidos em diversas circunstâncias e dificuldades, esses professores persistem na superação dos desafios profissionais, buscando proporcionar uma educação de qualidade aos seus alunos.

Palavras-chave: Memorial de formação. Formação docente. Trajetória formativa. Educação Matemática.

1 O presente trabalho foi realizado com apoio da Coordenação de Aperfeiçoamento de Pessoal de Nivel Superior Brasil (CAPES) - Código de Financiamento 001. 


\section{CHOICES, EXPERIENCES AND CIRCUMSTANCES IN THE TEACHER TRAINING MEMORIAL OF MATHEMATICS}

This article is consequence from results of a dissertation that had the objective to understand aspects of Mathematics teachers educational path through their life history narrative. Research was based on Autobiographical Method attended by six Mathematical teachers who wrote memorials of their professional training. Memorials were interpreted in the light of Analysis of Convergences and Singularities Method. To become a teacher demands a continuous and permanent motion and occurs through different experiences and scenarios that contribute to their formation as Mathematics teachers. In analyzing these narratives, we realize their family and teachers exerting a fundamental role in career choice. Training was influenced by teaching practice, by education interest or short experiences in classroom activities, by games as teachers or by other situations. Some elements such as affinities with Mathematics and feeling as a good student are strong factors in educational career choice. Although they were involved in different circumstances and difficulties, these teachers persist in overcoming professional challenges seeking to provide excellent education to their students.

Keywords: Memorial of Formation. Teaching formation. Educational Path. Mathematical Education. MEMORIAL DE FORMACIÓN DE PROFESORES DE MATEMÁTICAS

Este artículo es fruto de los resultados de una disertación que tuvo como objetivo tejer comprensiones de aspectos de la trayectoria formativa de profesores de Matemáticas al narrar su historia de vida por medio del memorial. La investigación se basó en el Método Autobiográfico y contó con la colaboración de seis profesores de Matemáticas que escribieron memorias de formación, interpretadas a la luz del Análisis de Convergencias y Singularidades. El movimiento de convertirse en profesor es permanente y se da por medio de las diversas vivencias, en que varios escenarios fueron construyéndose como profesores de Matemáticas. Al analizar estas narrativas, encontramos a la familia ya los profesores ejerciendo un papel fundamental en la elección por la profesión. La formación se da bajo la influencia de los profesores, el gusto por el área o las pequeñas vivencias de la profesión, sejam en las experiencias en el aula, en las bromas o en otros lugares. Algunos elementos como la aproximación 
y afinidades con la Matemática, la referencia a sí mismo como buen alumno son factores presentes en la opción por la carrera educativa. Aunque están involucrados en diversas circunstancias y dificultades, estos profesores persisten en la superación de los desafios profesionales, buscando proporcionar una educación de calidad a sus alumnos.

Palabras clave: Memorial de formación. Formación docente. Trayectoria formativa. Educación Matemática.

\section{Caminhos iniciais ...}

Labirinto

Não haverá nunca uma porta. Estás dentro E o alcácer abarca o universo E não tem nem anverso nem reverso Nem extremo muro nem secreto centro. Não esperes que o rigor de teu caminho Que teimosamente se bifurca em outro, Que obstinadamente se bifurca em outro, Tenha fim. É de ferro teu destino Como teu juiz. Não aguardes a investida Do touro que é um homem e cuja estranha Forma plural dá horror à maranha De interminável pedra entretecida."

Jorge Luis Borges (2010, p. 17)

Tão difícil quanto entrar em um labirinto, é sair dele... Vários são os caminhos e as possibilidades... Assim também é o processo investigativo, tão dificil quanto entrar em uma pesquisa e fazer escolhas dentre milhares de possibilidades, é finalizar esse percurso; trata-se de um trajeto cheio de incertezas... Vários caminhos surgem e se bifurcam... Várias são as possibilidades de problematização, que acabam não sendo registradas no trabalho final. Talvez seja por isso que há uma certa dificuldade em revisitar um trabalho finalizado... Ali passamos tempos a fio lamuriando, argumentando, pensando sobre aquilo que poderia ter sido melhor contemplado e sobre as precariedades ou incertezas que se mostraram no trabalho... Para muitos, é um processo desgastante, pois ali ficou materializado aquilo que se passava naquele momento...

Quase dois anos se passaram após a defesa deste trabalho ${ }^{2}$ e aqui propomos não lamentar sobre o que não foi realizado, mas evidenciar os feitos de uma dissertação ${ }^{3}$. Apresentamos a revisita de uma parte da dissertação, escolhendo aquilo que nos tocou para este momento de produção.

Essa pesquisa nasceu do desejo de conhecer as histórias de professores. Algo que surgiu ainda no período de graduação da primeira autora, ao elaborar um memorial de formação. Entendendo que "com a produção de uma escrita, constrói-se a experiência de formação" (CHENÉ, 2014, p. 123), a partir daqueles escritos, pensamos o quão interessante seria conhecer as tantas vivências dos professores que, em sua profissão, se reinventam cotidianamente. Deste modo, essa pesquisa foi se delineando

2 Esse trabalho se refere à dissertação da primeira autora deste artigo que foi orientada pela Profa. Dra. Rosana Areal de Carvalho e coorientada pela Profa. Dra Fernanda Aparecida Oliveira Rodrigues Silva: OLIVEIRA, Iara Leticia Leite de. Estações da escrita de si: trajetórias formativas de professores de Matemática em memoriais. 2017. 180 f. Dissertação (Mestrado em Educação) - Instituto de Ciências Humanas e Sociais, Universidade Federal de Ouro Preto, Mariana, 2017.

3 Esta pesquisa foi aprovada pelo Comitê de Ética em Pesquisa (CEP), com número CAAE 49390715.7.0000.5150, e transcorreu do modo previsto na Resolução do Conselho Nacional de Saúde 196/96. O Termo de Consentimento Livre e Esclarecido (TCLE) pode ser encontrado na dissertação. 
com o objetivo de tecer compreensões de aspectos da trajetória formativa ${ }^{4}$ de professores de Matemática, ao narrarem sua história de vida por meio do memorial. Tal interesse por essas histórias de vida deu-se, pois a escrita de si permite que o indivíduo "construa sua memória de vida e compreenda as vias que o seu patrimônio vivencial the pode abrir: ao fazê-lo no presente, ele está formando-se (emancipando-se) e projetando-se no futuro" (NÓVOA, 2014, p. 169). Nessa mobilização da escrita de si, um exercício um tanto quanto sinuoso, é possivel conhecer as distintas lembranças e vivências de um tempo... Do tempo de cada um e do nosso tempo.

\section{Alguns detalhes de uma viagem}

Na escrita da dissertação, utilizamos algumas analogias que partiram do trecho escrito por Silvana Duboc, que introduziu o trabalho: “A vida não passa de uma viagem de trem, cheia de embarques e desembarques, alguns acidentes, agradáveis surpresas em muitos embarques e grandes tristezas em alguns desembarques". Ao tomarmos a vida como uma viagem de trem, nos colocamos como maquinistas, assumindo a posição de traçar os itinerários possíveis, tendo sido a dissertação um diário dessa viagem investigativa. Os trilhos dessa locomotiva constituem os caminhos metodológicos eleitos para percorrer as trilhas da pesquisa, nos conduzindo para alguma direção. As estações são compostas por temáticas que estão fundadas por nossas escolhas teóricas; como maquinistas, delineamos os pontos de parada nos quais diversos referenciais embarcam ou desembarcam. Os vagões, que repre-

4 A trajetória formativa ou o percurso formativo são tratados como sinônimos. Não se referem a algo estático, mas a um caminho contínuo percorrido pelo sujeito. Assim como consideramos a formação um processo, nessa pesquisa, a trajetória formativa indica esse caminho percorrido pelos professores de Matemática, ao se formarem pelas diversas experiências e se constituírem professores. sentam o corpo de análise a partir dos dados coletados, percorreram os trilhos escolhidos pelas maquinistas, que cumpriram a função de preencher esses vagões e encaminhá-los no decorrer desse itinerário. E ainda contamos com os colaboradores que são aqueles passageiros com os quais tivemos um contato maior durante a viagem. Assim, cabe destacar que algumas partes dessa viagem estão registradas neste artigo.

A escolha ${ }^{5}$ desse grupo de passageiros, composto por seis professores de Matemática (Barnabé, Benta, Nastácia, Lobato, Monteiro e Pedro ${ }^{6}$ ) deu-se a partir da formação da primeira autora, que também é professora de Matemática, por estar mais próxima da realidade desse campo e pelo interesse em produzir conhecimento sobre a formação de professores de Matemática, contribuindo para ampliar as discussões na área. Como afirma Fiorentini (2003), os professores são sujeitos capazes de produzir e ressignificar, a partir da própria prática, saberes da atividade e do seu desenvolvimento profissional.

$\mathrm{O}$ ato de investigar é um passo em busca de sair de nós mesmos para enxergarmos ou-

5 Embora o convite tenha sido realizado a quinze professores, apenas seis aceitaram fazer parte da investigação. Os requisitos para selecioná-los foram ser professor de Matemática e ter lecionado durante algum tempo. Atendendo a essas condições, convidamos os mestrandos do Programa de Pós-Graduação em Educação Matemática da UFOP (Mestrado Profissional), pois, de acordo com o Regimento que normatiza a organização e o funcionamento desse programa, os discentes deverão ser graduados em Matemática (licenciatura ou bacharelado) e comprovar experiência docente em classes de Matemática, em instituições da Educação Básica ou do Ensino Superior. Em relação à paisagem, o desenvolvimento da pesquisa teve como cenário o contexto da Educação Básica atrelado ao Ensino Superior, que se mistura devido à experiência dos sujeitos da pesquisa, como professores, e por estarem em um programa de pós-graduação. Cabe ainda destacar que, como a produção de dados foi realizada no ano de 2015 , foram escolhidas as turmas de 2014 e 2015, sendo esse ano referente ao ingresso, por serem as turmas ativas no período citado.

6 Para não identificar os colaboradores da pesquisa, conforme normativa do CEP, utilizamos nomes fictícios. 
tras perspectivas. Uma viagem rumo ao desconhecido que, entre os embarques e desembarques, nos faz vivenciar uma aventura que supõe risco ou perigo, e na qual essas idas e vindas, paradas e passagens, exigem escolhas que delineiam nosso itinerário.

Assim como os maquinistas de um trem, podemos também viajar por onde desejarmos. Poderíamos caminhar dentre tantos trajetos, no entanto, escolhemos aquele que nos permitiu um itinerário, dando-nos diferentes elementos das histórias de vida de professores de Matemática. A pesquisa qualitativa tornouse nosso ponto de partida, pois, nessa viagem, a intenção foi explorar e olhar para o contexto do qual o professor faz parte. Tendo como objeto a trajetória formativa dos professores de Matemática, nos foi necessário esse exercício de olhar atentamente para cada trajetória que nos apontava a todo momento elementos latentes de como os professores se formaram. Seguindo esse caminho, optamos por direcionar nossa viagem pela abordagem do método autobiográfico com foco nas histórias de vida de professores de Matemática, sendo esse um método situado para além das metodologias experimental ou quantitativa (FERRAROTTI, 2014).

Essa metodologia evidencia não só os diferentes modos de utilização de narrativas, como também as dimensões interligadas aos indivíduos, dentre elas as sociais, culturais, históricas ou psicológicas. O termo "método autobiográfico" é justificado com base no valor dado à compreensão do interior da pessoa em relação às suas vivências e experiências. Trata-se de uma compreensão crítica, reflexiva e histórica, resultando em uma investigação do sujeito, e podendo trazer um aspecto formador (FINGER, 2014).

Cabe ressaltar que esse movimento da escrita de si é bastante amplo. Desde o final dos anos de 1970, a autoformação, os métodos bio- gráficos e as biografias educativas assumiram uma importância crescente no universo educacional. Ada Abraham, ao publicar, em 1984, o livro intitulado 0 professor é uma pessoa, desempenhou um papel pioneiro, quando houve uma guinada impulsionada por obras e estudos tratando sobre a vida, a carreira, o percurso profissional e o desenvolvimento pessoal dos professores, bem como de biografias e autobiografias docentes, colocando os professores no centro das discussões (NÓVOA, 1995).

Essa compreensão se reflete em algumas pesquisas, ao utilizarem os escritos dos sujeitos para produzir dados ou ainda, nas instituições, para fins acadêmicos avaliativos, como o uso de memoriais de formação em processos seletivos na graduação, pós-graduação ou etapas de concurso. A partir daí, podemos ver o importante espaço que tais documentos ocupam na comunidade educacional, como uma prática que assume diversas finalidades.

No Brasil, a partir de 1990, as pesquisas sobre a escrita de si no processo de formação e profissionalização docente expandiramse, dando um passo importante na valorização da escrita dos profissionais da educação (PASSEGGI; SOUZA; VICENTINI, 2011). Dada tal expansão, pode-se também presenciar uma heterogeneidade em torno da utilização de narrativas vindas de diferentes campos.

No campo educacional, como apresentam Nacarato, Passos e Silva (2014), as narrativas têm sido amplamente mobilizadas sob diferentes perspectivas, podendo ser usadas como prática de formação, pesquisa (pesquisa narrativa) ou fonte de dados. Sobre isso, Pineau (2006) tece considerações de que as histórias de vida se cruzam no âmbito da formação, da pesquisa e da intervenção, apresentando diversas correntes, na tentativa de refletir e de revelar o mundo vivido pelo sujeito, para então desencadear um processo de produção de sentido. De modo breve, trazemos alguns ele- 
mentos acerca dessa heterogeneidade presente no uso das narrativas.

Em um primeiro viés, há a utilização das narrativas como estratégias de formação, por permitirem compreender aspectos da trajetória formativa. Ao explorar a historicidade do sujeito mediante o narrar, este processo se torna um potencial instrumento de sua formação. A escrita da narrativa configurada como atividade formadora implica um processo de formação e conhecimento, pois possibilita ao sujeito entrar em contato com sua singularidade e mergulhar em sua interioridade para o conhecimento de si. Compreende, assim, um processo formativo em que o narrador toma consciência de si e de suas experiências, ao ser ator e investigador de sua própria história, por meio das experiências vivenciadas (SOUZA et al, 2010).

Em uma segunda perspectiva, temos a narrativa como pesquisa (pesquisa narrativa), entendida "como uma forma de compreender a experiência" (CLANDININ; CONNELLY, 2015, p. 51). Trata de um modo de (re)viver e (re)contar as histórias das pessoas e suas próprias histórias, ou seja, o pesquisador narrativo trabalha não apenas com seus colaboradores, mas consigo mesmo, visto que está imerso naquela comunidade investigada, fazendo parte do percurso, ou seja, ele também se autoforma. Desse modo, "trabalhar nesse espaço significa que nos tornamos visíveis com nossas próprias histórias vividas e contadas. Às vezes, isso significa que nossas histórias sem nome, e talvez secretas, vêm à luz assim como aquelas de nossos participantes" (CLANDININ; CONNELLY, 2015, p. 98). Na visão desses autores, a pesquisa narrativa caracteriza-se pelo espaço tridimensional (temporal, pessoal e social, lugar) e é por ele que o pesquisador aprende a olhar a si mesmo a partir de um conjunto de histórias (suas ou do outro).

Por fim, um outro grupo, no qual nossa in- vestigação se enquadra, faz uso da narrativa como fonte de dados, tendo em vista que o texto escrito deve "ser utilizado como objeto de análise considerando, sobretudo, o contexto de sua produção, sua forma textual e o seu conteúdo em relação ao projeto de pesquisa a que esteja vinculado" (SOUZA, 2006, p. 24). 0 pesquisador, ao utilizar essas fontes na pesquisa, pode identificar na narrativa os indícios das experiências dos sujeitos, ao longo de sua trajetória. Nessa dimensão, apreende por um outro lugar as diferentes representações e fenômenos que tecem a vida do sujeito, devido às suas experiências.

Para além disso, ainda há um movimento de diversas terminologias para o uso de narrativas que apontam para correntes com várias perspectivas teóricas e metodológicas (SOUZA et al, 2010). Podemos perceber que as narrativas se apresentam com diferentes nomes: histórias de vida, biografia, autobiografia e relato de vida, sendo apenas algumas que destacam o termo "vida" em seu nome. A diversificação de entradas e de terminologias assinala uma flutuação no sentido atribuído para expressar a temporalidade vivida pessoalmente (PINEAU, 2006). Assim, podem se dividir em três grupos, a partir de seu título. A entrada pelo pessoal consiste na conhecida literatura íntima, voltada para o "eu". Dela fazem parte as confissões, os diários íntimos, as cartas, as correspondências, os livros de pensamento, os livros de família, as relações etc. O aspecto voltado para o temporal inclui: genealogia, memórias, lembranças, diários de viagem, anais, crônicas, histórias. O último grupo tem a entrada pela própria vida, agregando ou não sua raiz grega, bios, fazendo parte dele as biografias, as autobiografias e hagiografias, os relatos de vida e as histórias de vida. A diferenciação dá-se pelo tipo de vida que privilegiam: global, singular, plural, educativa, formativa e profissional (PINEAU, 2006). 
Além do modo como são registrados, de forma oral ou escrita, há também uma polissemia que envolve o termo narrativa. Segundo Nacarato, Passos e Silva (2014), elas são tratadas como: narrativas de vida, de formação, de aulas, da experiência, narrativas docentes, (auto)biográficas, histórias de vida, histórias de professores, escrita do professor, memoriais (de formação), pesquisa narrativa e investigação biográfico-narrativa. Muitas vezes, há abrangência na utilização desses termos, não por serem sinônimos, mas por trazerem uma multiplicidade de significados e formas que direcionam para diferentes abordagens teóricas e metodológicas, implicando em distintas experiências de pesquisa (NACARATO; PASSOS; SILVA, 2014). Com isso, é importante o pesquisador ter cautela em seu uso, visto que esses distintos termos estão envoltos em concepções metodológicas e teóricas que alteram a produção de dados e sua compreensão.

\section{Dentre várias possibilidades de escrita... o Memorial de Formação}

Nossa produção de dados vem a partir dos memoriais de formação, que vamos caracterizar a seguir. Em torno dessa temática, do ato de narrar, há um fio importante a ser considerado: as histórias têm um destino, ou são contadas ou são lidas... Todo texto é "continuação de um diálogo, imaginário ou real, com interlocutores, reais ou imaginários, que tem, talvez, como possibilidade de sentido a ampliação do alcance de nossas interlocuções e produzir, em diálogo, novos sentidos acerca do tema posto e exposto na interlocução ocorrida" (PRADO; FERREIRA, 2014, p. 301). A narrativa é uma forma de organizar esses diálogos e histórias. Nela expomos, narramos ou relatamos algum fato, em um tipo de discurso que presume uma sucessão de acontecimentos, possibilitando o conhecimento destes (PRADO; SOLIGO, 2005).
A partir das histórias, escolhemos fragmentos em relação ao todo. Essas escolhas ocorrem porque a memória é seletiva. Ela não registra tudo, visto que é dependente do tempo e dos significados dados às vivências. Em meio a essa arte de narrar, temos a memória como potencializadora em comunicar aquilo que vivenciamos.

A escrita de memórias relatando eventos memoráveis é denominada memorial (PRADO; SOLIGO, 2005), logo, é uma forma de narrar a história pessoal por escrito. Na perspectiva desses autores, o memorial de formação é:

o registro de um processo, de uma travessia, uma lembrança refletida de acontecimentos dos quais somos protagonistas. Um memorial de formação é um gênero textual predominantemente narrativo, circunstanciado e analítico, que trata do processo de formação num determinado período - combina elementos de textos narrativos com elementos de textos expositivos. (PRADO; SOLIGO, 2005, p. 7)

Trata do registro de nossas próprias experiências e escrevê-lo é fazer o exercício constante de interrogá-las, para retomar as recordações e os fatos significativos que dão sentido às vivências do hoje. É uma atividade da linguagem na qual os fatos não são alterados, porém, as interpretações sim. Passeggi (2008) considera que o termo memorial (século XIV) advém, etimologicamente, do latim tardio memoriale designando "aquilo que faz lembrar" e o denomina como um gênero autobiográfico, sendo:

a arte profissional de tecer uma figura pública de si, ao escrever sobre recortes da vida: o processo de formação intelectual e o de inserção profissional no magistério. Percurso que inclui obrigatoriamente considerações sobre a vida familiar, escolar, profissional e coloca em foco questões como a formação inicial e continuada, o (des)emprego, a empregabilidade, as mudanças estatutárias, identitárias que fazem parte da história de vida ativa do adulto. (PASSEGGI, 2008, p. 27) 
Ao considerarmos a vida como uma viagem de trem, o memorial torna-se o registro das memórias dessa viagem e a materialização escrita das experiências do itinerário percorrido nos vagões profissional e pessoal. É interessante notar que, no trem, apesar dos vagões serem unidades distintas, estes percorrem a rota sob um mesmo eixo, ou seja, em nossa vida, temos os aspectos da dimensão profissional e pessoal, que estão unidos e nos formam como sujeitos.

Investigar o memorial é uma forma de conhecer a realidade da profissão. É um processo voltado para o futuro e para o passado, uma ação que pode possibilitar um outro olhar sobre os mesmos sonhos. Esse tipo de escrita nos insere como pesquisadores no campo profissional e pessoal do sujeito que descobre um vínculo entre o indivíduo e sua formação.

Mas o leitor pode se perguntar como foi a produção dessa escrita. Após o aceite desses seis professores, enviamos um questionário, por e-mail, que teve o intuito de traçarmos um "perfil" inicial de cada professor, possibilitando uma primeira aproximação do campo, ainda que com informações reduzidas do contexto vivenciado por eles. A seguir, enviamos o roteiro para que iniciassem a produção escrita do memorial de formação. O memorial foi um instrumento no qual cada colaborador da pesquisa escreveu sobre sua trajetória docente. Nosso interesse por ele é de “justamente deixar ao candidato o cuidado de tecer os fios que entrelaçaram os fatos entre si, explicitar o que e como provocaram efeitos formadores na sua vida intelectual e profissional" (PASSEGGI, 2008 , p. 31). Cabe ressaltar que, durante o percurso da pesquisa, mantivemos diálogo com os colaboradores via e-mail, tanto para auxiliá-los como para oportunizarmos uma proximidade entre as pesquisadoras e os sujeitos envolvidos na pesquisa.
Foram realizadas algumas intervenções, no processo de escrita, em forma de perguntas, sem julgamento de valor acerca do sentido dos elementos apontados no memorial. Podemos dizer que realizamos o processo de mediação biográfica, que se refere a uma ação que exige daquele que acompanha "ao mesmo tempo humildade para se submeter ao ritmo da subjetividade de cada membro do grupo reflexivo e postura ética na relação intergeracional, que se estabelece no processo de formação e inserção profissional do (futuro) professor no meio acadêmico" (PASSEGGI, 2008, p. 54). A mediação é um processo dinâmico de acompanhamento e de troca entre os sujeitos. Cabe ao pesquisador levar elementos para que o narrador possa pensar e desenvolver sua interpretação acerca dos aspectos relatados. $\mathrm{Na}$ mediação da escrita, via e-mail, conforme os memoriais "chegavam", realizamos sua leitura e apresentamos questões para esclarecer ou desenvolver a argumentação em algum trecho. Após essa intervenção, os memoriais foram reenviados aos professores para que realizassem as alterações e nos retornassem. Assim, foi desse modo que a mediação da escrita dos professores e nossas leituras e intervenções ocorreram.

Nessa viagem investigativa, era importante escolher lentes para olhar a paisagem e compreender seus detalhes. Essas lentes foram diretrizes que nos ajudaram a aprofundar os dados. A análise dos memoriais deu-se a partir da orientação metodológica desenvolvida pela análise de singularidades e convergências de Martins-Salandim (2007; 2012), que lança o olhar do pesquisador aos elementos subjetivos da narrativa e para além daquilo que foi dito. 0 pesquisador, ao analisar os dados, não se volta apenas para o diálogo ocorrido no cenário de pesquisa, mas para as diversas situações ali manifestadas; trata-se de um movimento analítico tortuoso, repleto de idas e 
vindas. Nesse movimento de compreender os significados dessas narrativas, nos direcionamos para a análise das singularidades que se desdobram em um processo de produzir uma narrativa sobre e a partir de cada escrita, em torno de "quais questões, individualmente, cada uma delas dispara em nossa pesquisa. Neste sentido, buscamos registrar nossas percepções de como cada narrativa apresenta-se, seu fio condutor, suas marcas" (MARTINS-SALANDIM, 2012, p. 242). Pelo memorial de formação, olhamos a perspectiva impressa de cada professor, ao escrever sua história, e buscamos detalhes do fio que o conduziu ao narrar. Nessa etapa, foi possível registrar elementos que nos levaram a pensar sobre aspectos da formação de professores de Matemática, bem como ressaltar a subjetividade de cada professor, preservando sua natureza singular.

Outro movimento deu-se pela análise de convergências, que consiste em olhar para os "elementos que se mostravam mais insistentemente numa série de fontes ou elementos que, nesse mesmo conjunto, se mostravam claramente divergentes; ou seja, uma análise que só pode ser conduzida a partir de um cotejamento entre fontes" (MARTINS-SALANDIM, 2012, p. 63). A percepção da trajetória de formação desses professores de Matemática ocorreu pelo cotejamento dos memoriais, leitura que nos possibilitou delinear um panorama de aspectos da formação, a partir da identificação dos temas mais recorrentes.

\section{Sobre a formação docente}

O campo da formação docente constitui-se em um cenário carente de mudanças e marcado por transformações e descontinuidades. Sendo a escola um espaço de trabalho, cabe a essa instituição a reprodução das normas e a transmissão cultural, acompanhando a produção da sociedade. Assim, não é possível dis- correr sobre esse processo sem antes observar os aspectos do tempo, lugar e espaço, postos em um contexto de tensão e lutas, pois a história da profissão é inseparável do lugar ocupado por seus membros (NÓVOA, 1991).

De acordo com Nóvoa (2003), a formação de professores é uma área que sofre intensamente com as alterações provocadas pela sociedade que tem, nas instituições formativas, os espaços propícios da constituição de uma profissão e da formação profissional. Entretanto, ainda falta a consciência crítica de que as licenciaturas são berços valiosos para concebê-las.

Entendemos a formação como uma construção contínua, revelada nas histórias de vida dos diferentes sujeitos (DOMINICÉ, 2014). Deste modo, ela é marcada por contratempos, impedimentos, resistências, aceitações e construções, incluindo a presença do "outro", que ajuda a dar sentido à profissão. Concordamos com a reflexão de Dominicé (2014, p. 90), ao pontuar que "a formação depende do que cada um faz do que os outros quiseram, ou não quiseram, fazer dela". Ou seja, corresponde a um processo no qual se dá forma à vida.

Estar em constante formação, possibilita aos profissionais, de modo geral, construir novos conhecimentos e saberes diante dos desafios surgidos, tanto na prática profissional quanto social, que se refletem no campo profissional. Ou seja, tal movimento pode ser entendido, segundo Nóvoa (2014, p. 159), “como uma contribuição exterior que pode modificar certas trajetórias de vida pelas quais os adultos se constroem pouco a pouco".

Tardif (2014) também discute a ideia de formação como um continuum, em que o professor intercala as fases de trabalho com as de formação, ao longo de sua trajetória profissional. Logo, não se restringe apenas aos conhecimentos iniciais adquiridos na universidade e, sim, aos que também percorrem toda a carrei- 
ra profissional do docente. A formação acontece em diversos espaços, seja pelos pares, cursos, pelo ambiente de trabalho, pela pesquisa, entre outros. Sob esse aspecto, destacamos as experiências com o outro como fontes de aprendizagem do trabalho docente.

De acordo com Chené (2014), o conhecimento do professor funda raízes pela articulação entre os âmbitos pessoal e social e apresenta progressos a partir dos sentidos dados pelo sujeito. 0 professor, no exercício da profissão, engloba a mistura do "eu" pessoal com o "eu" profissional. A profissão docente é alterada constantemente pelo espaço social em que está inserida. Sob esse ponto de vista, “a formação é como um pequeno quadro dentro de um quadro maior, isto é, insere-se na vida da pessoa, desenvolve-se com ela, articulase em profundidade com a sua problemática existencial" (CHENÉ, 2014, p. 122). A tentativa de compreensão da experiência docente é um modo de apreender o "eu" dado pelo entendimento das mudanças ocorridas no cotidiano e no próprio percurso de vida.

Um dos modos de remexer no caminho de construção do ser profissional é no ato da escrita, que, em nosso caso, se dá pelo memorial de formação. A escrita é um modo de teorizar aquilo que se fez durante a trajetória de vida, através de reflexão, autorreflexão e pensamento crítico. Consiste na negociação de significados e no confronto de ideias consigo mesmo, trazendo novos elementos para a reflexão durante a produção das memórias. Com a prática da escrita, podemos nos tornar aprendizes de nós mesmos a partir de nossas memórias. É uma ação que, ao refletir e criar novas estruturas, o sujeito vai criando a si mesmo e aprendendo sobre o seu "ser" ou seu "eu". Assim, nessa dinâmica, o lugar da experiência é o "eu".

Entendemos a formação como um percurso em que o sujeito adquire e desenvolve habili- dades e conhecimentos para operar com seu "objeto" de trabalho, em um contexto situado. Nesse percurso, o professor constrói, ressignifica e modifica os saberes necessários ao exercício da profissão, os quais são importantes no desenvolvimento do profissional e na construção do "eu" singular.

\section{Os professores e seus "dois dedinhos" de prosa no memorial}

Nessa empreitada investigativa, nossos colaboradores nos ajudaram a conhecer um pouco dos aspectos da formação de professores de Matemática. A partir da escrita de si, percebemos elementos de suas vidas pessoal e profissional, as relações constituídas, as práticas de formação e os diferentes momentos de suas vivências. Apesar da singularidade e individualidade,7 os professores apresentaram aspectos que permitiram compreendê-los como um grupo e chegaram a elementos comuns que nos levaram a conhecer essas trajetórias. E é sobre esses aspectos que iremos tratar neste trabalho, ou seja, iremos apresentar as convergências dessas narrativas, tratando daquilo que apareceu de modo mais insistente nelas.

Ao narrarem sua trajetória, os professores tocam em questões relativas a sua origem, sua opção pela profissão, as experiências positivas ou negativas e até mesmo em algumas percepções da profissão. De acordo com Tardif e Raymond (2000), a socialização pré-profissional é um movimento formativo que comporta continuidades e rupturas que ocorrem em toda a história de vida do sujeito. Tal socialização compreende as experiências familiares

7 Trata-se de uma descrição das singularidades que consiste em um exercício de criação de narrativas "individuais", por meio dos memoriais, anunciando o fio condutor pelo qual cada professor conduziu sua narrativa. $\mathrm{Na}$ dissertação, os memoriais de formação estão disponíveis na íntegra; apresentamos inicialmente o memorial de cada professor, para depois nos debruçarmos naqueles aspectos convergentes das narrativas. 
e escolares dos docentes como um processo pelo qual os saberes são produzidos. Por isso, pode-se dizer que o saber profissional está "na confluência entre várias fontes de saberes provenientes da história de vida individual, da sociedade, da instituição escolar, dos outros atores educativos, dos lugares de formação etc." (TARDIF; RAYMOND, 2000, p. 215).

\section{A presença da família}

Todos os professores trazem a família em sua narrativa, como um grupo importante desse movimento formativo. A família possibilita a inserção no período de escolarização, ocupa também a posição de incentivar ou não os estudos, a carreira docente, seja na escolha da profissão, na continuidade do exercício da docência, dentre outras perspectivas. Nessa fase de formação, a família aparece como um grupo que também percorre esse caminho.

Em relação a essas vivências no seio familiar, Pedro comenta que esses laços favoreceram a aproximação, o gosto e a aprendizagem da Matemática, através das atividades do trabalho familiar. Narra que "o gosto pela Matemática teve fundamento na minha vivência familiar, morando em sítio e lidando com a plantação de café e a criação de animais. Nesse sentido, [...] foram ferramentas naturais para o aprendizado da Matemática me fazendo ter contato desde muito cedo com as operações Matemáticas. Somar, subtrair, multiplicar e dividir era muito comum para mim, ensinado pelo meu pai, um homem que mesmo não tendo a oportunidade de frequentar a escola tinha muito conhecimento da Matemática, de forma prática é claro, nas experiências comerciais que desde muito cedo fez parte da sua vida. [...] Na venda dos frangos tinha que lidar com a operação de multiplicação com quilogramas e gramas combinado com o valor que era em cruzeiros e centavos, logo aprendi operar com os números racionais decimais mesmo sem saber que o nome era esse [...] Na colheita do café tinha que medir o que era colhido pelos trabalhadores [...] No final da semana era necessário calcular o valor a ser pago, o que combinava as medidas inteiras e não-inteiras e os valores pagos por cada caixa de café colhida. Logo, foi muito natural para mim tomar gosto pela $\mathrm{Ma}$ temática, pois era o meu dia-a-dia".

Esse aspecto da família também aparece em Lobato. Em seu memorial, apresenta os cuidados da avó ao ensinar a tabuada ao neto: “Lembro-me que já tinha facilidade em aprender a tabuada e fazer operação de Matemática. Minha avó materna sempre estudava comigo e tinha muita paciência para me ensinar a tabuada". Além da dedicação, há destaque para a paciência da avó durante a atividade, ou seja, não se tratava apenas de ensinar, mas também de ter paciência e atenção ao sentarse junto com ele. Sobre os primeiros tempos de aprendizagem, Melo (2008) apresenta em sua pesquisa que os professores se referem à família como um grupo importante de sua formação devido aos primeiros ensinamentos, pelo incentivo e motivação para frequentar a escola. No caso de Lobato, sua família vivia em um sítio, de onde vinha a fonte de renda. Em busca de melhores condições de vida, o avô convidou-o a morar na capital para continuar estudando.

As memórias de Benta a levam para os tempos da infância. Para ela, sua vida acadêmica teve início quando sua mãe a matriculou na pré-escola. Desde então, os pais, os irmãos e o marido sempre a apoiaram durante a graduação e o mestrado. Barnabé era envolto pelos cuidados da família em relação a sua formação, que o incentivava e dialogava sobre o assunto, “... sempre fui incentivado por meus pais a ir à escola, local de aprendizado". Como a mãe era professora da escola onde estudava, sempre "andava na linha" e se via rodeado de 
“cobranças em casa por bom rendimento e por uma pressão interna, natural de quem se via cercado na escola por pessoas ligadas à minha mãe". Isso se estendia ao acompanhamento do cotidiano escolar, por parte de sua família. Notamos que o reconhecimento familiar auxiliou esses professores na travessia de barreiras e dificuldades da formação.

Em relação à influência familiar, no que se refere à escolha da profissão, a maioria alega ter escolhido o curso pelas condições do momento. Nastácia conta que as difíceis circunstâncias financeiras e sociais a levaram a escolher uma profissão que proporcionasse um ingresso rápido no mercado de trabalho. Como "Minha família sempre foi pobre, então eu precisava de uma profissão que não precisava de altos investimentos [...] precisava de uma profissão que desse retorno financeiro o mais rápido possivel para poder ajudar minha família". Justifica que, se a sua condição financeira fosse melhor, talvez sua opção teria sido outra. Pesou também em sua decisão o fato de ter o curso na faculdade da cidade em que morava, pois, com isso, não teria despesas extras.

Em vários momentos, a fala sobre o custo do curso repete-se e acaba não sendo algo exclusivo de Nastácia, visto que essas situações permeiam outros memoriais, como os de Lobato e Monteiro. Ao escolher o curso, Lobato tinha dúvidas e receios. Apenas levava a certeza da área (Exatas): “Fiquei em dúvida entre Matemática, Física e Engenharia Elétrica, porém, devido ao valor do curso e instituições que os ofereciam optei por fazer Matemática [...] Engenharia era muito caro e pouquíssimas faculdades ofereciam o curso de Física, por isso resolvi fazer Matemática". A opção profissional veio pela afinidade com a área, mas estava restrita pelo custo e pelas opções de oferta na universidade. Salienta que, no decorrer do curso, gostou da profissão. Para Monteiro, não é diferente, "[...] a escolha estava relacionada com a afinidade que eu tinha com a Matemática, além de o preço da mensalidade era bem baixo". Nesse contexto, sua escolha aparece nos liames da afinidade e do custo do curso.

Enquanto esses professores narram as dificuldades decorrentes da escolha profissional, lembramos de Barnabé, que conta sobre sua opção, permeada por outro fio: o projeto dos pais para sua carreira. Sua família sempre incentivava e a dialogava sobre sua formação. “Com a parte da Matemática mais evoluída $e$ não me desviando muito do objetivo de estudar Engenharia, incentivado por minha mãe, prestei vestibular para Matemática na UFOP e fui aprovado em 2007. Essa escolha foi por conta de ser um curso afim a qualquer curso de Engenharia, podendo me proporcionar uma transferência interna para o curso que meus familiares queriam, mas não eu!" Sendo assim, buscava mostrar à família que o seu bem-estar seria atuar em uma profissão em que tivesse gosto e familiaridade. 0 projeto familiar, quanto à escolha profissional, acaba sendo motivado pela expectativa dos pais em relação ao futuro dos filhos.

Para sustentar as necessidades materiais, muitas vezes, a escolha pela docência é garantia de se inserir rapidamente no mercado de trabalho. Diante do contexto, era viável escolher cursos com mensalidades mais baixas e ofertados em instituições localizadas na cidade ou arredores. Era a oportunidade a se "agarrar" àquele momento, tendo em vista a necessidade de aproveitar a ocasião. Entretanto, isso não torna a escolha menos autêntica, pois o percurso de vida se faz em meio a projetos planejados e a acontecimentos circunstanciais, o que não implica que esse último aspecto não seja pensado, pois a autenticidade da escolha se constrói e é afirmada nas ações cotidianas.

No decorrer dos anos, as transformações ocorridas na sociedade alteraram as relações 
de trabalho. Estas estão interligadas às mudanças do mercado de trabalho, do contexto político, econômico, social e cultural, ou seja, "vive-se uma conjuntura histórica permeada por cenários de relações sociais e de trabalho, complexos e contraditórios, que geraram uma nova compreensão de carreira e de desenvolvimento profissional" (GATTI et al, 2010, p. 142).

A partir das ideias de Lisboa (2002), Gatti et al (2010) acrescentam que, ao olhar para a realidade, o contexto, a prioridade e a viabilidade, a escolha profissional torna-se limitada. Essas limitações não estão apenas no plano da profissão, diante do mercado de trabalho presente ou futuro, como também "por objetivos que vão desde as expectativas familiares até o que existe de mais viável dentro da sua realidade, sendo, muitas vezes, até contraditório com seus desejos e possibilidades pessoais" (LISBOA, 2002, p. 44 apud GATTI et al, 2010, p. 143). O que está na direção do que foi delineado acima é que as escolhas são feitas a partir de situações planejadas e circunstanciais.

Vemos, nesse sentido, que a família tem um papel fundamental. Nas narrativas de professoras presentes na dissertação de Costa (2012), transparecem fatores de influência da situação econômica na decisão de serem professoras. Elas buscavam a formação para garantir rápida entrada no mercado de trabalho, sendo que muitas vezes a escolha do curso se dava pela falta de oferta de outros cursos na cidade ou nos arredores. Desse modo, a decisão pela profissão docente "decorre de fatores ligados ao campo econômico em que a busca pelo trabalho é para sanar as necessidades materiais do ser humano" (COSTA, 2012, p. 111). A família é esse primeiro meio de formação dos professores, dando suporte aos desafios e dificuldades enfrentadas. Além disso, ela transcende os limites e os cuidados do núcleo familiar e se estende a outras situações, que influenciam o sujeito em suas experiências e escolhas.

\section{Dos encontros com a Matemática}

No que se refere à aproximação e às afinidades com a Matemática, um ponto recorrente se refere à escolha da profissão atrelada a outros fatores como a afinidade com a Matemática, às pequenas experiências na sala de aula e até mesmo por influência dos professores. Afinal, "o jovem não baseia sua decisão apenas nos familiares. Ele é influenciado pelos pares, que são os 'outros' significativos na sua vida" (SANTOS, 2005, p. 59). Esses "outros" podem ser os professores, o gosto pela área ou as pequenas vivências da profissão, sejam nas experiências em sala de aula, nas brincadeiras ou em outros locais.

Em seu trabalho, Soares (2012, p. 55) observa que a constituição das professoras de sua pesquisa se configura "na trajetória de vida e de trabalho, agregando, para isso, diversas experiências pessoais e profissionais obtidas ao longo do percurso e que, de alguma forma, influenciaram a escolha da carreira docente e a permanência nela". As narrativas trazem suas vivências, como alunas da Educação Básica, e os professores do percurso escolar, que se tornaram modelos por suas atitudes positivas ou negativas, dentre outros fatores. Essas questões também permeiam os memoriais desse trabalho, em que as experiências durante a trajetória escolar proporcionam compreensões da profissão de professor. Diante disso, vamos continuar...

No período da Pré-escola, Monteiro inicia sua narrativa destacando esse gosto pela $\mathrm{Ma}$ temática e narra uma primeira proximidade com a disciplina no gosto pelo desenho "[...] desenhava muito, principalmente palhaços $e$ figuras geométricas, esses meus desenhos ficavam tão bem coloridos que ganhavam estrelinhas e parabéns". Sobre a relação com a Matemática, Benta narra que no Ensino Fundamental I "Adorava os momentos de competição para ver quem acertava a tabuada toda", demonstrando seu gosto por essa área. 
Assim como Monteiro e Benta, Nastácia também se identifica com o ambiente escolar por meio das vivências proporcionadas em sala de aula. Ela diz que aproveitava a oportunidade de ensinar os colegas: "[...] me lembro de quando meus colegas não entendiam alguma disciplina sempre me dispunha para ajudar. [...] pois dessa forma além de ajudá-los estaria estudando. Eu sentia um bem-estar em poder ajudar meus colegas que tinham muita dificuldade em Matemática". Sobre o último ano do Ensino Médio, "[...] pensei em ser professora e escolhi Matemática, pois era a matéria que mais gostava e tirava as melhores notas. Eu escolhi ser professora porque eu gostava de apresentar trabalhos para turma toda, acho que me identifiquei com o contexto". Nastácia e os outros professores, em vários momentos, destacam a Matemática como a disciplina que mais gostavam. Ao trazerem essa frase, podemos perceber que não era apenas uma disciplina que tinham preferência ou proximidade, mas que de fato eles se encontravam nela.

Nastácia demonstra uma afinidade progressiva com essa disciplina, ao escrever: "[...] a minha relação com a Matemática melhorou a cada ano, não por motivação dos professores, mas porque gostava do desafio que era resolver um exercício e encontrar a resposta certa. $O$ livro de Matemática tinha as respostas no final então ficava raciocinando de acordo com a matéria até conseguir resolver o exercício". Era uma relação de superação frente aos desafios de resolver os exercícios. Algo semelhante ocorre em sua vida: sempre encara os acontecimentos como desafios, de modo que consiga superá-los.

Apesar de Barnabé narrar "Minha relação com a Matemática sempre foi de 'amizade'. Me adaptava bem aos exercícios propostos e sempre tirei boas notas até o término do Ensino Fundamental. Digo amizade, pois não me fazia mal e a cada problema a resolver tinha uma troca: a disciplina me trazia uma contextuali- zação para as questões e eu superava/resolvia o que era para resolver naquele momento"; na mudança de escola, descobriu uma nova Matemática, devido ao modo como os professores trabalhavam essa área, prezando por cálculos “mais bem justificados, ou seja, cada linha de resolução tinha sua importância, diferentemente de apenas se achar a resposta certa". Ele se adaptou a essa forma de analisar a Matemática, mas "sem deixar de encará-la ainda como um conjunto de regras, fórmulas e padrões"; ou seja, deixa muito clara sua posição em relação à forma como entendia a Matemática.

Barnabé descreve que o gosto pela Matemática e seu olhar diferente para esse campo do conhecimento ocorreu quando se tornou monitor. "Com o trabalho de esclarecer as dúvidas dos alunos de Ensino Médio, que tomei gosto por Matemática [...] Ser monitor me fez praticar algo que é tarefa do professor: explorar os raciocínios dos estudantes. Gostava de ensinar. Esse gosto veio no momento em que percebi que não há respostas prontas, mas sim pensamento e sentimentos diversos nas mentes de cada um ao resolver as questões. Veio daí um dos principais motivos que me fez pensar em ser professor". A motivação de ser professor foi despertada pela oportunidade de olhar a Matemática sob um outro ângulo e posição.

Essas experiências e motivações podem não ser determinantes, mas permitem apontar caminhos ou aproximações com o campo e com a profissão. A escolha profissional perpassa por laços sociais e também afetivos, ao ter o professor como influência e nos pequenos gostos e gestos vividos no dia a dia da escolarização. Isso também pode ser visto em Grandin (2008). Ao analisar os memoriais de seus colaboradores, esta autora percebe que, na sua constituição como docentes, há uma forte influência exercida pelos professores que tiveram, seja na aproximação da disciplina ou pela própria profissão, pois “o conhecer 'ser-pro- 
fessor' já começa quando estes sujeitos ainda são alunos" (GRANDIN, 2008, p. 75).

Algumas dessas questões, como o gosto pela Matemática, estão presentes no trabalho de Silva (2010). Pesquisando sobre professores de Matemática, percebeu que "o que os aproximou da área de Matemática foi a relação que estabeleceram desde muito cedo com ela [...]. Ao se contarem, narrarem e mostrarem como se constituíram, esses sujeitos demonstraram que gostavam da Matemática" (SILVA, 2010, p. 217).

\section{Imagens de si frente à Matemática}

Durante a escrita dos memoriais, nossos colaboradores apresentam algumas imagens de si. Podemos notar que, no percurso de suas vidas, são unânimes as referências acerca de serem bons alunos: dão ênfase nas notas que obtinham, no gosto pela Matemática ou pela área de Exatas. Em algumas histórias, isso se resume a gostar de estudar e até mesmo à intensidade dos estudos para atingir determinado objetivo.

Nastácia descreve: "Não me recordo como eram as aulas, mas me lembro que sempre tirei boas notas. [...] E no Ensino Médio me dedicava mais ainda aos estudos para conseguir entrar em uma faculdade. Eu gostava mais de Matemática, Física e Química [...]. Eu estudava muito, acho que umas oito horas por dia, para poder conseguir passar no vestibular para licenciatura em Matemática. E deu muito certo passei em décimo terceiro lugar em quarenta vagas na UNIPAC em um curso noturno de Licenciatura em Matemática".

Já Lobato nos conta que "No Ensino Médio me destaquei positivamente como aluno, principalmente, nas disciplinas de Física e Matemática [...] Nos trabalhos e provas minhas notas eram excelentes". Mas essa condição se altera na graduação: "Me senti muito mal, pois era a primeira vez que tirava notas péssimas". Essa situação acontecia em decorrência do intenso ritmo de trabalho, que o impedia de ter momentos de estudo fora da universidade. 0 estágio remunerado possibilitou maior dedicação e empenho nos estudos e, com isso, se tornou um graduando mais comprometido e confiante.

Pedro também se insere nesse contexto, ao contar que acordava cedo para realizar as atividades do sítio e, ao retornar da escola, almoçava e dava continuidade aos afazeres. Além disso, traz os detalhes de como ia para a escola, em um período em que não havia transporte escolar. "A partir da antiga 5 a série passei a estudar a noite, o que apertou um pouco mais quanto a cumprir os horários das tarefas em casa. Cursei meu Ensino Fundamental e Médio em minha cidade natal e como vivia na zona rural eu ia caminhando para a escola, pois naquela época isso era comum e não havia o transporte escolar e também meus pais não tinham condições de me levar. Estudei de manhã até a 4á série onde já me destacava na aprendizagem da Matemática por desde muito cedo aprender com meu pai trabalhar as operações matemáticas".

Lobato vivia com a família na zona rural e na 4a série mudou para uma escola que se localizava na cidade. "Estudei nessa escola até concluir o Ensino Médio, mas todos os dias eu ia e voltava em uma van disponibilizada pela prefeitura, pois essa escola ficava longe da minha casa. No Ensino Médio me destaquei positivamente como aluno, principalmente nas disciplinas de exatas: Matemática, Física e Química. [...] Participei, durante o Ensino Médio, de três feiras de Física, que aconteciam anualmente, sendo que meus trabalhos sempre ficavam entre os primeiros colocados". Essa postura permaneceu na graduação: "As disciplinas de Cálculo, Álgebra e Análise foram excelentes, as que mais me destaquei durante o curso. Consegui boas notas em todas as demais e nunca fui reprovado". 
Ao ingressar em uma nova instituição, no Ensino Médio, Barnabé percebeu que a forma como havia sido ensinado não era a mais adequada, o que se refletiu em seus rendimentos: "nos dois primeiros bimestres obtive rendimentos em $\mathrm{Ma}$ temática nunca vistos, abaixo da média de $60 \%$ exigida. No ciclo anterior, tal rendimento era superior a 90\%, só que no ensino tradicional, mecânico [...]. Essa mudança foi encarada com dificuldade, com tristeza, como um fator de incapacidade. Como um aluno que obtinha um bom rendimento até o 8o ano podia estar com tantas dificuldades no Ensino Médio?". As notas, naquela época, representavam para ele seu nível de aprendizagem, por isso dava importância aos resultados. Concluiu a Educação Básica sem nenhuma reprovação. Tal afirmação perpassa o memorial de Lobato e Nastácia.

Nossos colaboradores apresentam visões em torno de suas capacidades acerca dos sucessos e destaques ou não em relação à aprendizagem da Matemática. Há traços das condições dificeis que enfrentavam para ir à escola, devido às condições familiares que vivenciavam. Esses fragmentos trazem algumas afirmações sobre si, principalmente, acerca daquilo que consideravam como sucesso, ou seja, tirar boas notas. Em contraposição, devido às adversidades de trabalho e estudo isso muitas vezes não era possível.

É importante discutir a fase pré-profissional, pois aquilo que os docentes sabem acerca de diferentes elementos que envolvem a profissão advém de suas histórias de vida, principalmente enquanto estudantes, pois estão imersos em seu ambiente original de trabalho durante sua escolarização (TARDIF; RAYMOND, 2000). A partir da ideia de imersão no ambiente original, abre-se um amplo leque para discutir a formação de professores. Assim, na perspectiva de Melo (2008), acrescenta-se, ao ambiente, a imagem construída acerca do que é ser professor de Matemática, enquanto es- tudantes, que também recebem influência de seus professores.

Ao longo desse percurso, diante das experiências vivenciadas, nossos sujeitos não são meros receptores passivos. Pelo contrário, são espectadores ativos que constroem sua trajetória profissional e criam referências acerca daquilo que consideram, como alunos, professores e escola, com base em sua vivência em meio à escolarização ou à vida familiar. A velha frase "na minha época era assim...", não corresponde a um sentimentalismo ou saudosismo, mas é uma colocação que nos leva a pensar que essa foi a imagem construída pelo sujeito ao longo de sua trajetória acerca do que considera como escola e educação.

\section{Um diário de viagem}

Finalizar um texto nem sempre é um movimento fácil, pois, como mencionamos no início, nele materializamos aquilo que nos tocou naquele momento. Essa tarefa vai se tornando um labirinto, com suas idas e vindas, que vão se bifurcando em várias possibilidades. Para tanto, decidimos seguir o conselho de Jorge Luis Borges (2010, p. 17): “Não esperes que o rigor de teu caminho, Que teimosamente se bifurca em outro, Que obstinadamente se bifurca em outro, Tenha fim". Não propomos um fim, mas um ponto de continuação para outras reflexões...

Ao analisarmos essas narrativas, tendo em vista a compreensão da pessoa, no que se refere às suas vivências e experiências, como nos aponta Finger (2014), buscamos destacar alguns elementos que nos chamaram a atenção nos escritos dos memoriais. Ao olharmos para eles, pudemos refletir sobre os aspectos das trajetórias desses professores de Matemática, ou seja, investigar o memorial nos possibilitou conhecer a realidade da profissão e verificar que essa reflexão não se restringe apenas a esse campo de formação de profes- 
sores, como também amplia nossa discussão a outras áreas.

O movimento de tornar-se professor é permanente e se dá por meio de diversas vivências, em que vários cenários os vão construindo enquanto professores de Matemática. As configurações do percurso de vida de cada professor têm movimentos singulares, em que cada narrativa expressa sentimentos e sentidos próprios. Os acon(tecimentos) tecem melindrosamente essas trajetórias, assim cada história se forma em uma dinâmica própria, que dialoga entre si nas experiências.

Percebemos, ao longo dessas narrativas, que esse professor de Matemática se constitui à medida que adquire, incorpora, modifica e adapta os saberes em função de sua carreira como profissional. Nessa trajetória, vários elementos são evidenciados: a família e os professores, com um papel fundamental na formação, a aproximação e construção de afinidades com a Matemática; a referência a si mesmo, como um bom aluno; a escolha da profissão e, durante a carreira, o gosto pelo ensinar e pela profissão.

A escolha da docência, muitas vezes, é a garantia de se inserir rapidamente no mercado de trabalho, condição dada pela necessidade de sustentar-se materialmente, mas também pelo fato do curso de Matemática, em geral, ter um custo relativamente baixo e possuir facilidade de ingresso. Tais decisões não se configuram como uma escolha menos autêntica, mas se dão pelas circunstâncias, urgências e emergências daquele momento. A escolha da profissão ocorre sob a influência de professores, o gosto pela área ou as pequenas vivências da profissão, seja nas experiências em sala de aula, nas brincadeiras ou em outros locais. Observamos nas narrativas que são unânimes as referências ao fato de terem sido bons alunos, dando ênfase às notas que obtinham, ao gosto pela Matemática ou pela área de Exatas. Em algumas histórias, isso se resume a gostar de estudar e até mesmo à intensidade dos estudos para atingir determinado objetivo.

Apesar das contingências vividas por esses professores, vemos a escola como um espaço que ainda desenvolve no sujeito o gosto pelo conteúdo (Matemática ou pela área de Ciências Exatas), pelo cotidiano escolar e pelo ensinar, elementos que marcam suas narrativas. E embora estejam envoltos por todas essas circunstâncias, esses professores têm persistido na superação dos desafios da profissão e da sociedade, buscando permanecer na docência e dar o melhor de si mesmos, para se desenvolverem enquanto professores, além de proporcionarem uma educação de qualidade aos seus alunos.

Ao (re)visitarem esses diferentes encontros, consigo e com o outro, em seu processo formativo, o processo de escrita se consolidou também em um processo de formação, à medida que esses professores, ao lembrarem os acontecimentos de sua vida, perceberam e refletiram sobre o percurso profissional realizado. Nesse contexto, percebe-se a presença do "outro" como marcante na formação, pois o "outro" é em nós uma presença formativa. Afinal, nossa história de vida constrói-se em um campo altamente relacional, ou seja, não nos formamos sem a presença do outro.

\section{Referências}

BORGES, Jorge Luis. Elogio da sombra. São Paulo: Cia. das Letras, 2010.

CHENÉ, Adèle. A narrativa de formação e a formação de formadores. In: NÓVOA, António; FINGER, Matthias. (Orgs.). 0 método (auto)biográfico e a formação. Tradução de Maria Nóvoa. 2. ed. Natal: EDUFRN, 2014. p. 121-132.

CLANDININ, D. J.; CONNELLY, F. M. Pesquisa narrativa: experiência e história em pesquisa qualitativa. Tradução do Grupo de Pesquisa Narrativa e Educação de Professores ILEEI/UFU. Uberlândia, MG: EDUFU, 2015. 
COSTA, Maria Lemos da. Formação de professores alfabetizadores: a trajetória formativa em serviço. 2012. 210 f. Dissertação (Mestrado em Educação) Programa de Pós-Graduação em Educação, Universidade Federal do Piauí, Teresina, 2012.

DUBOC, Silvana. Trem da vida. Disponível em: <https://educacao.estadao.com.br/blogs/blog-doscolegios-santa-maria/trem-da-vida/>. Acesso em: 31 mar. 2019.

DOMINICÉ, Pierre. O processo de formação e alguns dos seus componentes relacionais. In: NóvOA, António; FINGER, Matthias. (Orgs.). 0 método (auto) biográfico e a formação. Tradução de Maria Nóvoa. 2. ed. Natal: EDUFRN, 2014. p. 77-90.

FERRAROTTI, Franco. Sobre a autonomia do método biográfico. In: NÓVOA, António; FINGER, Matthias. (Orgs.). 0 método (auto)biográfico e a formação. Tradução de Maria Nóvoa. 2. ed. Natal: EDUFRN, 2014. p. 29-55.

FINGER, Matthias. As implicações socioepistemológicas do método biográfico. In: NÓvOA, António; FINGER, Matthias. (Orgs.). 0 método (auto)biográfico e a formação. Tradução de Maria Nóvoa. 2. Ed. Natal: EDUFRN, 2014. p. 111-119.

FIORENTINI, Dario. Memória e análise da pesquisa acadêmica em Educação Matemática no Brasil: o banco de teses do CEMPEM/FE - Unicamp. Zetetiké, v. 1, n. 1, p. 55-76, mar. 1993.

FIORENTINI, Dario. (Org.). Formação de professores de matemática: explorando novos caminhos com outros olhares. Campinas, SP: Mercado de Letras, 2003.

GATTI, Bernadete Angelina et al. A atratividade da carreira docente no Brasil: estudos e pesquisas educacionais. Fundação Victor Civita, São Paulo, n. 1, p. 1-82, 2010.

GRANDIN, Luciane Aparecida. As representações sociais no processo de formação docente em serviço: um estudo com memórias de formação. 2008. 113 f. Dissertação (Mestrado em Educação) - Faculdade de Educação, Universidade Estadual de Campinas, Campinas, 2008.

MARTINS-SALANDIM, Maria Ednéia. Escolas técnicas agrícolas e educação matemática: história, práticas e marginalidade. 2007. 265 f. Dissertação (Mestrado em Educação Matemática) - Instituto de Geociências e Ciências Exatas, Universidade Estadual Paulista, Rio Claro, 2007.

A interiorização dos cursos de Matemática no Estado de São Paulo: um exame da década de 1960. 2012. 379 f. Tese (Doutorado em Educação Matemática) - Instituto de Geociências e Ciências Exatas, Universidade Estadual Paulista, Rio Claro, 2012.

MELO, Maria José Medeiros Dantas de. Olhares sobre a formação do professor de Matemática - Imagem da profissão e escrita de si. 2008. 322 f. Tese (Doutorado em Educação) - Centro de Ciências Sociais Aplicadas, Universidade Federal do Rio Grande do Norte, Natal, 2008.

NACARATO, Adair Mendes; PASSOS, Cármen Lucia Brancaglion; SILVA, Heloisa da. Narrativas na pesquisa em Educação Matemática: caleidoscópio teórico e metodológico. Bolema, Rio Claro, SP, v. 28, n. 49, p. 701-716, ago. 2014.

NÓVOA, António. Para o estudo sócio-histórico da gênese e desenvolvimento da profissão docente. Teoria e Educação, n. 4, p. 109-139, 1991.

Vida de professores. 2. ed. Porto: Porto Editora, 1995.

O passado e o presente dos professores. In: NÓVOA, António. (Org.). Profissão Professor. Porto: Porto Editora. 2003. p. 13-34.

A formação tem que passar por aqui: as histórias de vida no Projeto Prosalus. In: NÓVOA, António; FINGER, Matthias. (Orgs.). 0 método (auto) biográfico e a formação. Tradução de Maria Nóvoa. 2. ed. Natal: EDUFRN, 2014. p. 143-175.

OLIVEIRA, Iara Leticia Leite de. Estações da escrita de si: trajetórias formativas de professores de Matemática em memoriais. 2017. 180 f. Dissertação (Mestrado em Educação) - Instituto de Ciências Humanas e Sociais, Universidade Federal de Ouro Preto, Mariana, 2017.

PASSEGGI, Maria da Conceição. Memoriais autobio-gráficos: a arte profissional de tecer uma figu- 
ra pública de si. In: PASSEGGI, Maria da Conceição; BARBOSA, Tatyana Mabel Nobre. (Orgs.). Memórias, memoriais: pesquisa e formação docente. Natal: EDUFRN; São Paulo: Paulus, 2008. p. 27-42.

PASSEGGI, Maria da Conceição; SOUZA, Elizeu Clementino de; VICENTINI, Paula Perin. Entre a vida e a formação: pesquisa (auto)biográfica, docência e profissionalização. Educação em Revista, Belo Horizonte, v. 27, n. 1, p. 369-386, abr. 2011.

PINEAU, G. As histórias de vida em formação: gênese de uma corrente de pesquisa-ação formação existencial. Educação e Pesquisa, São Paulo, v. 32, n. 2, p. 329-343, mai./ago. 2006.

PLACCO, Vera Maria N. de Souza; SOUZA, Vera Lucia Trevisan. Aprendizagem do adulto professor. São Paulo: Loyola, 2006.

PRADO, Guilherme do Val Toledo; FERREIRA, Cláudia Roberta. Narrativas docentes: contornos e entornos. In: VICENTINI, Adriana A. Fernandes; EVANGELISTA, Francisco. (Orgs.). Um baú de histórias: narrativas e formação. Campinas, SP: Mercado de Letras, 2014.

PRADO, Guilherme do Val Toledo; SOLIGO, Rosaura. Memorial de formação: quando as memórias narram a história da formação.... In: PRADO, Guilherme do Val Toledo; SOLIGO, Rosaura. (Orgs.). Porque escrever é fazer história: revelações, subversões, superações. Campinas, SP: Graf, 2005.

SANTOS, Larissa Medeiros Marinho dos. O papel da família e dos pares na escolha profissional. Psico- logia em Estudo, Maringá, v. 10, n. 1, p. 57-66, jan./ abr. 2005.

SILVA, Diva Souza. A constituição docente em Matemática à distância: entre saberes, experiências e narrativas. 2010. 278 f. Tese (Doutorado em Educação) - Faculdade de Educação, Universidade Federal de Minas Gerais, Belo Horizonte, 2010.

SOARES, Rosana Maria Cavalcanti. A constituição do ser professor: uma análise do percurso de formação e trabalho de docentes da educação básica. 2012. 245 f. Dissertação (Mestrado em Educação) Faculdade de Educação, Universidade Federal do Ceará, Fortaleza, 2012.

SOUZA, Elizeu Clementino de. (Org.). Autobiografias, histórias de vida e formação: pesquisa e ensino. Porto Alegre: EDPUCRS; Salvador: EDUNEB, 2006.

SOUZA, Elizeu Clementino de et al. Fios e teias de uma rede em expansão cooperação acadêmica no campo da pesquisa (auto)biográfica. Teias, Rio de Janeiro, ano 11, n. 21, p. 1-17, jan./abr. 2010.

TARDIF, Maurice. Saberes docentes e formação profissional. Petrópolis, RJ: Vozes, 2014.

TARDIF, Maurice; RAYMOND, Danielle. Saberes, tempo e aprendizagem do trabalho no magistério. Revista Educação \& Sociedade, ano XXI, no 73, p. 209244, dez. 2000.

Recebido em: 15.01.2019

Aprovado em: 26.03.2019

Iara Letícia Leite de Oliveira é Mestre em Educação e doutoranda do Programa de Pós-Graduação em Educação Matemática da Universidade Estadual Paulista “Júlio de Mesquita Filho" - Campus Rio Claro. GHOEM - Grupo História Oral e Educação Matemática. e-mail: iaral.oliveira@yahoo.com

Universidade Estadual Paulista “Júlio de Mesquita Filho" - campus Rio Claro - Avenida 24A, 1515, Bela Vista, Rio Claro, SP, CEP: 13506-900. Tel: (19) 98396-6391

Rosana Areal de Carvalho é Doutora em Ciências Humanas. Professora no Departamento e Educação da Universidade Federal de Ouro Preto. GERAES - Grupo de estudos e pesquisas em História da Educação. e-mail: rosanareal@ufop.edu.br Universidade Federal de Ouro Preto - Rua do Seminário s/n, Mariana, MG, CEP: 35420-000. Tel: (31) 99748-8180

Fernanda Aparecida Oliveira Rodrigues Silva é Doutora em Educação. Professora no Departamento de Educação da Universidade Federal de Ouro Preto. FOPROFI - Grupo de Pesquisa Formação e Profissão Docente. e-mail: fernandasilva@ ufop.edu.br

Universidade Federal de Ouro Preto - Rua do Seminário s/n, Mariana, MG, CEP: 35420-000. Tel. (31) 97523-8681 